pp 710-719. ( ) Royal Aeronautical Society 2017. This is an Open Access article, distributed under the terms of the Creative Commons Attribution-NonCommercial-NoDerivatives licence (http://creativecommons.org/licenses/by-nc-nd/4.0/), which permits non-commercial re-use, distribution, and reproduction in any medium, provided the original work is unaltered and is properly cited. The written permission of Cambridge University Press must be obtained for commercial re-use or in order to create a derivative work.

doi: 10.1017/aer.2017.16

\title{
Development of a simulation platform of all-electric aircraft on-board systems for energy management studies
}

\author{
F. Schettini \\ f.schettini@ing.unipi.it \\ E. Denti and G. Di Rito \\ University of Pisa \\ Dipartimento di Ingegneria Civile ed Industriale \\ Sez. Aerospaziale \\ Pisa \\ Italy
}

\section{ABSTRACT}

This paper deals with the development of a simulation platform for the dynamic analysis of systems characterised by different physical domains. The research has been carried out in the context of the EC-funded Clean Sky Joint Technology Initiative (Green Regional Aircraft/All-Electric Aircraft domain). In particular, the objective of the research is focused on the on-board systems of new All-Electric Aircraft, where a crucial design point is related to the electrical energy management. In the "all-electric" concept, where pneumatic and hydraulic power systems are eliminated to improve aviation costs and environmental impact, the dynamics of electrical power absorptions is to be characterised and managed to avoid excessive peaks with respect to generators capabilities. The paper describes the architecture of a Matlab/Simulink simulation platform developed in order to design and validate of the electrical energy management logics, which lead up to $32 \%$ reduction of the maximum power request for the case study considered. Thanks to an approach based on a mixing of cosimulation and S-function compiling, the platform integrates models coming from different environments (AMESim, Dymola/Modelica), and developed by various partners/specialists.

Keywords: Aircraft systems; all-electric; multi-physics modelling; co-simulation 


\subsection{INTRODUCTION}

A critical design issue for modern system engineers is often related to the performance analysis of complex and articulated plants, where equipments/systems coming from different physical domains (thermodynamic, aerodynamic, hydraulic, electrical, etc.) work and interact. A quite relevant example is given by the on-board systems of an All-Electric Aircraft (AEA). The goal of the AEA concept is to improve aviation costs and environmental impact through the elimination of pneumatic and hydraulic power with the complete electrification of aircraft systems $^{(1-4)}$. The elimination of compressor bleeding increases the engine efficiency (lower $\mathrm{CO}_{2}$ emission and lower costs), while the removal of hydraulic power systems reduces waste disposal problems related to hydraulic fluids. These objectives can be achieved only by optimising the power capability of AEA generators, which implies the need to properly monitor and manage the electrical power requests, by avoiding temporary overloads, or possible lack of energy for safety-critical systems. Moreover, the absence of electrical energy management logics would result in very large peaks of power absorption that would lead to oversized electrical generators.

This paper presents a simulation platform for the power absorption assessment of AEA systems, which is conceived as design tool to develop and validate electrical energy management logics to be implemented into the future AEAs. This research was funded by the Clean Sky Joint Technology Initiative (http:/www.cleansky.eu/), which is an aeronautical research programme aiming to develop technologies for a significant increase of the environmental performances of air transport, resulting in less noisy and more fuel-efficient aircraft.

In the cooperating framework of the simulation platform, each system model has been separately developed by the project partners using different approaches and software languages, so the basic requirements for the platform were that it should be capable of integrating models coming from different environments AMESim $^{(5)}$, Dymola ${ }^{(6)}$, Matlab/Simulink $\left.{ }^{(7)}\right)$, and it should have the maximum level of flexibility and modularity (e.g. easy and independent update). The integration of complex models describing physical phenomena with quite different frequency contents clearly causes concerns about finding the initial equilibrium condition and defining solver settings such as the numerical method and the time step. All these aspects are discussed in the paper, proposing a solution that aims at limiting the computation time. In addition, the paper describes a possible electrical power management strategy and shows its efficacy in terms of the reduction of the maximum power requested to the electrical generators.

\subsection{SIMULATION PLATFORM}

\subsection{Modelling complexity levels}

The models developed during the research activity have been characterised by three levels of complexity:

- Architectural models (Level 1) - simplified models capable of representing the steadystate response and the low-frequency dynamics (up to $1 \mathrm{~Hz}$ ), mainly used for preliminary definition of the system architecture;

- Functional models (Level 2) - more enhanced models capable of representing the medium-frequency dynamics (up to $100 \mathrm{~Hz}$ ), used to define the basic strategies of energy management; 
- Behavioural models (Level 3) - detailed models capable of representing the highfrequency dynamics (up to $1 \mathrm{kHz}$ ), mainly used to evaluate the electrical power quality and the electrical network stability.

The platform has been developed to be flexible and modular so that the complexity level of each system model can be selected by the user. According to the objectives of the analysis, the platform can thus be set from "totally Level 1" to "totally Level 3".

\subsection{Platform architecture}

The simulation platform, referred to the on-board systems of an all-electric regional aircraft, includes the following models:

- Electrical Power Generation System (EPGS)

- Energy Management System (EMS)

- Flight Control System (FCS)

- Landing Gear System (LGS)

- Ice Protection System (IPS)

- Environmental Control System (ECS) with related Cabin Thermal model (CT)

- Other Systems, representing constant power requests related to avionics, fuel system, equipment/furnishing, internal lights and entertainment

The simulation platform is referred to an AEA with conventional turbo-prop engines, so it does not include a model of the propulsion system. In addition, the design objective of the EMS does not address possible dynamic interactions between electrical power requests and engine power output (torque and RPM).

Once given the time histories of pilot commands, environmental conditions and flight conditions, the systems models allow an evaluation of the thermal and electrical power flows as functions of the voltages made available by the EMS. The models also provide further outputs related to performances, in order to assess if the systems are working in compliance with their design requirements (e.g. speed and position of movable parts, mechanical stress, electrical stress, mass flow). Table 1 reports the list of the system models developed within the research, with indications about developers, simulation environments and complexity level.

The platform uses Matlab/Simulink as the integration environment, and its top-level block diagram is shown in Fig. 1.

The "Mission Profile" block together with the "RPM" block give the input time histories (pilot commands, reference cabin temperature, outside environmental conditions, etc.). These inputs are obtained by an offline simulator of a regional turbo-prop aircraft developed by the authors, which reproduces typical flight missions.

The "Cabin Temperature Controller" block regulates the ECS target temperature by elaborating the difference between the reference cabin temperature given by the "Mission Profile" and the actual one coming from the "Cabin Thermal model". The "ECS" block implements a closed-loop temperature control by regulating the temperature and the mass flow of the air sent to the cabin.

The "Cabin Thermal model" evaluates the cabin temperature as a function of outside conditions and ECS airflow, by taking account of solar radiation, thermal flows through 


\section{Table 1 \\ Systems models integrated in the simulation platform}

\section{System}

Energy Management System (EMS)

Cabin Thermal model (CT)

Electrical Power Generation System (EPGS)

Ice Protection System (IPS)

Environmental Control

System (ECS)

Flight Control System (FCS)

Landing Gear System (LGS)

Other Systems
Complexity level

Level 2

Level 2

Level 2

Level 1

Level 2

Level 2

Level 2

Level 3

Level 2

Level 3

Level 1
Simulation environment

Dymola/Modelica

AMESim

Matlab/Simulink

\section{AleniaAermacchi}

\begin{tabular}{|c|c|}
\hline Dymola/Modelica & AleniaAermacchi \\
\hline Matlab/Simulink & $\begin{array}{c}\text { Liebherr-Aerospace } \\
\text { Toulouse SAS }\end{array}$ \\
\hline Matlab/Simulink & University of Pisa \\
\hline Dymola/Modelica & TWT/Bausch Gall \\
\hline Matlab/Simulink & University of Pisa \\
\hline Dymola/Modelica & TWT/Bausch Gall \\
\hline Matlab/Simulink & AleniaAermacchi \\
\hline
\end{tabular}

EADS CASA

\section{Developed by}

AleniaAermacchi

AleniaAermacchi

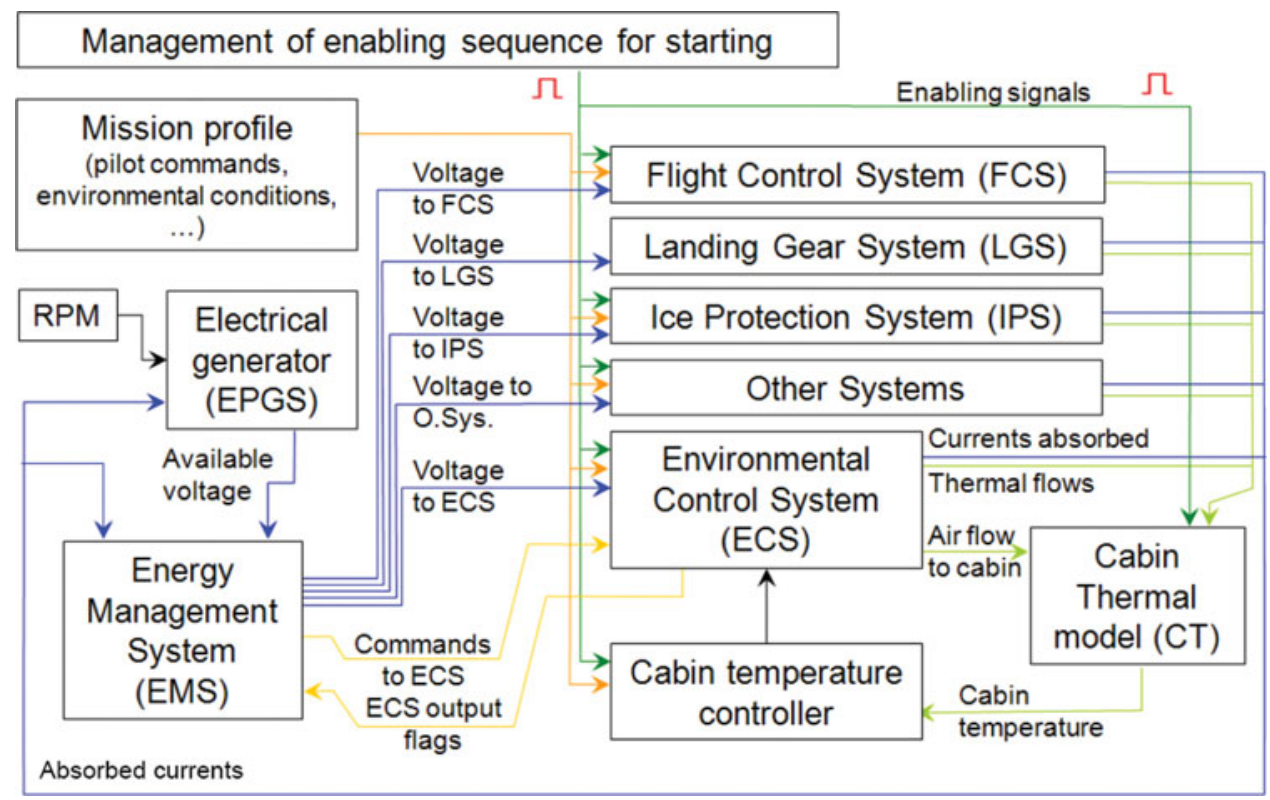

Figure 1. (Colour online) Top-level block diagram of the simulation platform.

cabin walls, heat transport through the different cabin compartments, and heat produced by passengers, avionics and utilities.

The electrical power absorptions of all systems is fed back to the "EPGS" block, which provides the available supply voltage. These voltage and current levels are elaborated by 
the "EMS" block, which applies the energy management strategies and regulates the voltage supplied to the various systems (see Section 3.1).

The "LGS" and "FCS" blocks include models of the electro-mechanical actuators for the landing gear and the flight controls (tricycle landing gear, two ailerons, two elevators, one rudder, four flaps and four spoilers) ${ }^{(8-12)}$.

The "IPS" block includes the model of an electro-thermal system with anti-icing/de-icing capabilities, while the "EPGS" block simulates a $270 \mathrm{~V}_{\mathrm{DC}}$ generator with rectifier diode and control unit. Special attention must be addressed to the block named "Management of enabling sequence for starting", which is used to find the equilibrium of the systems models before the test starts (Section 2.3).

Several tests have been performed to assess the effects on the computation time of solver settings and models integration method.

\subsection{Models integration, solver setting and computation time}

The process of integrating into Simulink models coming from Dymola/Modelica and AMESim can be done with two different methods: the first one is to compile the models and to import them into Simulink as S-Functions blocks, and the second one is the co-simulation.

The main difference between the two approaches is that, in the first case, all the models use the Simulink numerical solver, while in the second case, each model uses the solver of its own development environment.

The co-simulation demonstrated to be the most convenient integration method for the Cabin Thermal model, which is very complex and originated in AMESim. This is because, during the simulation, the AMESim software implements automatic algorithms to select the adequate solver settings, to optimise numerical performance. This optimisation is lost if the model is compiled and imported into Simulink. On the contrary, the S-Functions compiling method has given good results for Dymola models as EMS, IPS, FCS and LGS because Dymola models can be compiled by selecting the solver method, fixed or variable step, according to the type of the solver method to be used in Simulink.

Concerning the solver setting, it basically depends on the granularity (e.g. number of variables), complexity (e.g. nonlinearities) and frequency content of the models. In the platform, some models have high complexity and high-frequency content (EPGS, FCS and LGS require integration steps from $10^{-4}$ to $10^{-5}$ seconds), but are characterised by low granularity. On the other hand, some models have low-frequency content, but high granularity and complexity (ECS and CT). In this situation, fixed-step solvers are not convenient in terms of computation time: if a small integration step is applied to the whole platform, the models characterised by high granularity cause a dramatic increase of the computation time. For this reason, the platform uses a variable-step solver. In particular, by using the Simulink ode23 solver with default settings, a ratio of about 5 between computation time and simulation time has been obtained ${ }^{1}$.

\subsection{Technique for finding initial equilibrium of systems}

Models complexity clearly causes some concerns about finding the initial equilibrium condition for the whole platform. At the initial equilibrium, the systems can be characterised by nonzero values of inputs, outputs and internal states, and an analytical evaluation of these

\footnotetext{
${ }^{1}$ Performed with a modern dual-processor PC (six-core system).
} 


\section{Table 2 \\ Models enabling sequence during the initial settling time}

\section{System}

Energy Management System (EMS)

Electrical Power Generation System (EPGS)

Other Systems

Flight Control System (FCS)

Landing Gear System (LGS)

Environmental Control System (ECS)

Cabin Thermal model (CT)

Ice Protection System (IPS)

\section{Enabling sequence}

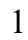

2

3

4

5

6
Enabling

time [sec]

0

10

20

30

40

150 (test start)

quantities would be burdening, and it would imply extra work for partners (also to harmonise the exchange of such data among the systems).

The solution used was to let the platform itself find the systems equilibrium, by simulating the dynamics for an initial settling time that is then neglected in the analysis. During this initial settling time, the mission profile inputs are kept constant and equal to the first value of their time history.

To reduce the computation cost related to the initial settling time, the models are progressively enabled in accordance to the sequence reported in Table 2 . This sequence is defined to start the simulation of low-frequency/high-granularity models (ECS and CT) only after the high-frequency content models (FCS and LGS) have reached the equilibrium. In such a way, when the initial transients of the high-frequency models are simulated (and extremely small integration steps are used by the solver), the low-frequency/high-granularity models are not active yet. This approach gives relevant benefits in terms of computation time, and it also enhances the numerical stability of the platform. For similar reasons, as pointed out by Table 2, ECS is enabled before CT, so that ECS reaches a steady-state air mass flow output, before the $\mathrm{CT}$ is activated. In this condition, the temperature control provides the ECS with a null command.

\subsection{ENERGY MANAGEMENT STUDY: AN EXAMPLE}

This section presents an example of results provided by the simulation platform. The AEA systems architecture refers to a 90-pax turboprop regional aircraft with an engine failure, which is the dimensioning case for the design of the energy management strategies (the onboard available power is halved).

\subsection{Basic EMS strategies}

The EMS, including the energy management logic, the Solid State Power Controllers (SSPCs) and the High-Voltage DC Bus-bar, continuously monitors the EPGS current and its time derivative. When an overload condition is detected, the logic operates firstly on the SSPCs contactors to obtain a faster power absorption reduction (high-frequency action). If the overload persists, the logic's request the ECS to reduce its absorbed power (low-frequency action). To implement this low-frequency action, specific operative modes (Command to 


\section{Table 3 \\ Estimate of on-board systems power budgets}

$\begin{array}{lccc}\text { Systems } & \begin{array}{c}\text { Max continuous } \\ \text { power }[\mathbf{k W}]\end{array} & \begin{array}{c}\text { Peak } \\ \text { power }[\mathbf{k W}]\end{array} \\ \text { A } & \text { Equipment/Furnishing } & 3 & 3 \\ \text { B } & \text { Internal lights } & 2 & 2 \\ \text { C } & \text { Entertainment } & 1 & 1 \\ \text { D } & \text { IPS } & 35 & 50 \\ \text { E } & \text { ECS } & 75 & 75 \\ \text { F } & \text { EPGS (internal loss) } & 1 & 2 \\ \text { G } & \text { FCS } & 4 & 20 \\ \text { H } & \text { LGS } & - & 3 \\ \text { I } & \text { Avionics and External lights } & 2 & 2 \\ & \text { TOTAL } & 123 & 158\end{array}$

ECS, Fig. 1) are selected for the ECS by the EMS. This because it is not possible to obtain a reduction of the electrical power absorbed by the ECS by simply reducing its available voltage. The ECS sends warnings to the EMS when it cannot further reduce the absorbed power without causing a compressor stall or out-of-range cabin temperature (ECS output flags, Fig. 1). The EMS never decreases the power required by safety-critical systems as FCS and LGS.

The EMS high-frequency action, implemented on SSPCs contactors, is related to:
a) Equipment/Furnishing
b) Internal lights
c) Entertainment
d) IPS

The final effect determines a supply voltage fading on these loads, which can result up to a total shut-off on the first three ones, and to a 50\% voltage supply reduction for IPS. If relevant power absorption peaks are present, this strategy is not effective, so the EMS also acts on the ECS with a low-frequency mode. These EMS regulating actions only occur when the absorbed power is greater than $105 \mathrm{~kW}$. This threshold has been set on the basis of the estimates of the systems power absorptions (Table 3). The reported data also point out that a conventional design approach (without EMS actions) based on electrical power budgets should lead to the need of a generator with $160 \mathrm{~kW}$ Maximum Continuous Power Rating (MCPR). This would result in using $77 \%$ of MCPR in the maximum continuous power conditions, and $98.7 \%$ of MCPR in peak power conditions.

The high-frequency EMS action can reduce the max continuous power rating up to $68 \%$ MCPR, this is obtained by the complete shut-off of loads A, B and C, and to a $8 \mathrm{~kW}$ power reduction of load $\mathrm{D}$ (Table 3 ). Nevertheless, the peak power rating up is lowered only to $90 \%$ MCPR. To manage the peak power, the low-frequency EMS action on ECS determines an additional power reduction (up to $35 \mathrm{~kW}$ ), so that the two combined actions are capable of reducing the peak power rating up to $68 \% \mathrm{MCPR}$. 

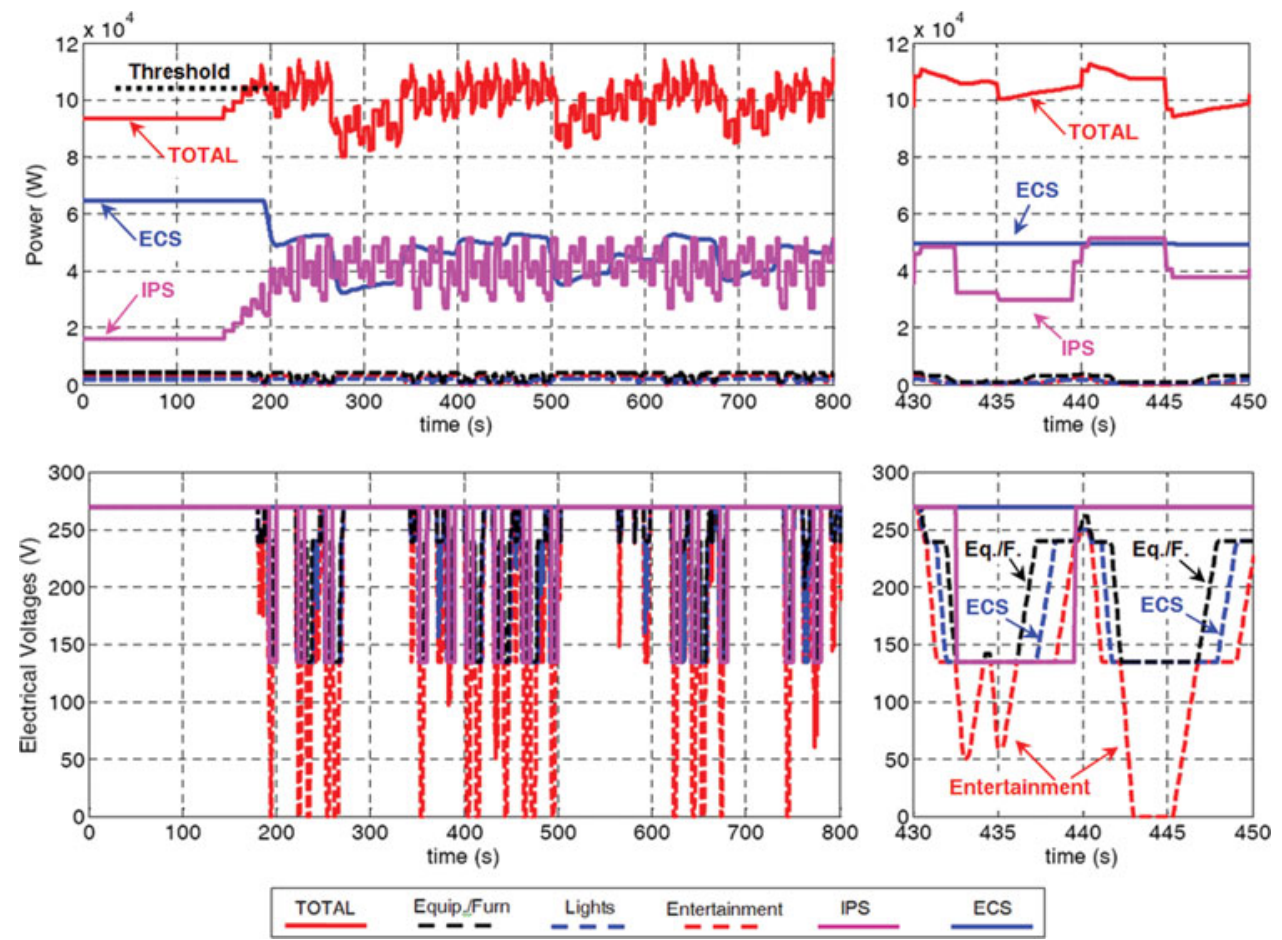

Figure 2. (Colour online) Simulation results: power requests and supply voltages of AEA on-board systems.

\subsection{Simulation results}

Figure 2 reports an example of platform results, for the reference aircraft trimmed at sea level in "cold day" condition $\left(\mathrm{OAT}=253^{\circ} \mathrm{K}\right)$. The upper plots show the total absorbed power and the EMS-relevant power requests (IPS, Equipment/Furnishing, Internal Lights, Entertainment, ECS $)^{2}$, while the lower plots report the electrical voltages supplying the same systems. When the total power reaches the activation threshold $105 \mathrm{~kW}$ (at about $180 \mathrm{sec}$ ), the EMS acts (high-frequency action) by fading the voltages of loads A, B, C and D (Table 3), and it also commands the ECS to reduce its power absorption to about $50 \mathrm{~kW}$ (low-frequency action). When this ECS power reduction is achieved (from 200 to $250 \mathrm{sec}$ ), the total absorption is not sufficiently decreased to restore the voltage of loads A, B, C and D. Thus, the ECS power is again reduced and the other loads are re-energised (from 250 to $350 \mathrm{sec}$ ). Afterwards, the EMS tries to increase again the power available for the ECS until the activation threshold is reached once more. This leads to a total absorption with cyclic behaviour, having a maximum peak of $115 \mathrm{~kW}$, and a mean value of about $100 \mathrm{~kW}$, which is in the range of the EMS activation threshold.

It is important to observe that the regulations of the ECS power do not imply significant variations of the aircraft cabin parameters, as shown in Fig. 3. In particular, the EMS operation causes temperature variations smaller than $1^{\circ} \mathrm{C}$, with a rate ranging from -0.5 to $1{ }^{\circ} \mathrm{C} / \mathrm{min}$, and pressure variations smaller than $20 \mathrm{mbar}$ (corresponding to an equivalent altitude variation

\footnotetext{
${ }^{2}$ Other power requests are not shown because they are not influenced by EMS strategies.
} 

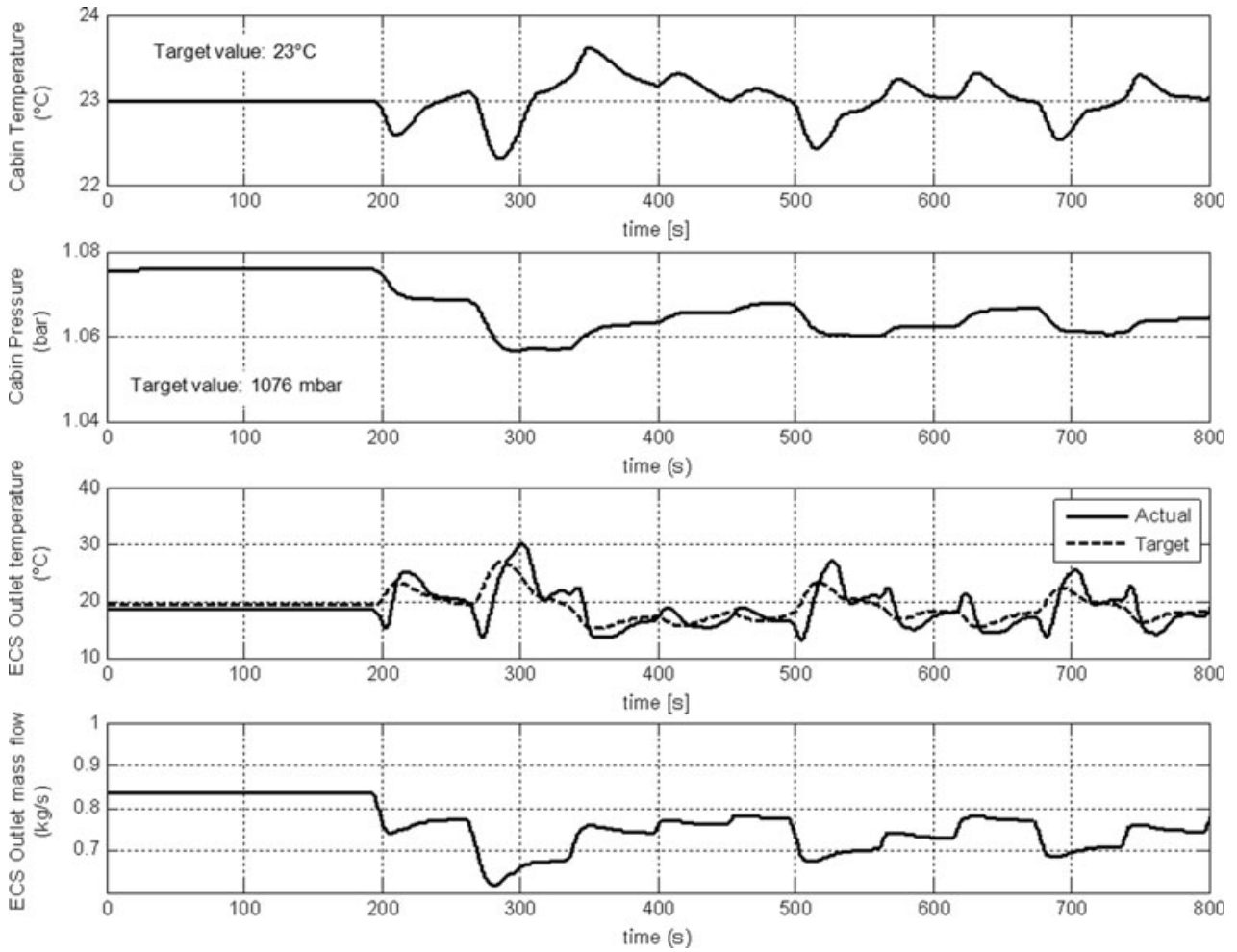

Figure 3. Simulation results: cabin and ECS outputs.

of 200 meters), with a rate ranging from $-20 \mathrm{mbar} / \mathrm{min}$ to $10 \mathrm{mbar} / \mathrm{min}$. In addition, Fig. 3 illustrates the ECS outlet mass flow and the comparison between the actual ECS outlet temperature and its target value commanded by the cabin controller. The ECS mass flow behaviour has a strict correlation with the ECS target temperature signal, because a mass flow reduction implies a target temperature increase to maintain the heat flow transferred to the cabin.

\subsection{CONCLUSIONS}

A Matlab/Simulink simulation platform has been developed to integrate models coming from different environments (AMESim, Dymola/Modelica), thanks to an approach based on a mixing of co-simulation and S-function compiling. The platform covers the on-board systems of an all-electric regional aircraft, and it has been used to design and validate electrical energy management logics. Models characterised by different physical domains, frequencycontent, complexity and granularity are integrated aiming at modularity and flexibility. In addition, good computational performance is obtained on a single PC application (a ratio of about to 5 is obtained between the computation and simulation time). This result has been achieved also thanks to a particular strategy used for finding the initial equilibrium of systems. This is determined by the platform itself via dynamic simulation, during an initial settling time in which the systems models are progressively activated. The enabling sequence of the models has been defined by taking into account their specific features, an aspect that can be 
critical in terms of computation time. The results show that EMS operation allows up to $32 \%$ reduction of maximum power absorption, with negligible degradation of on-board systems performances. In particular, the EMS modulation of ECS power does not imply significant variations of the aircraft cabin pressure and temperature.

A future goal of this work is to increase the Test Readiness Level (TRL) of the simulation platform models, which are currently characterised by a low TRL, because the main objective was to demonstrate the energy management concepts. Ongoing activities are carried out within the prosecuting EC-funded research programme Clean Sky 2, in which on-board allelectric systems prototypes will be developed and tested. When the experimental data is available, the validation of the models will be performed in terms of complexity level and numerical performances ${ }^{(13)}$. In addition, the simulation platform could be applied for the assessment of the on-board energy consumption of pioneering aircraft configurations, as those characterised by hybrid propulsion, including the models of electric and thermal engines.

\section{ACKNOWLEDGEMENTS}

This work has been developed in the context of the EC-funded Clean Sky Joint Technology Initiative (Green Regional Aircraft /All-Electric Aircraft domain). The authors wish to thank all the partners involved into the project.

\section{REFERENCES}

1. Shaw, J.C., Fletcher, S.D.A. Norman, P.J. and Galloway, S.J. More electric power system concepts for an environmentally responsible aircraft $(\mathrm{N}+2)$, Proceedings of $47^{\text {th }}$ International Universities Power Engineering Conference (UPEC), 2012, London, United Kingdom, pp 1-6.

2. Rosero, J.A., Ortega, J.A., Aldabas, E. and Romeral, L. Moving towards a more electric aircraft, IEEE Aerospace and Electronic Systems Magazine, 2007, 22, (3), pp 3-9.

3. Howse, M. All electric aircraft, IEE Power Engineering Journal, 2003, 17, (4), pp 35-37.

4. Emadi, A. and EhSANI, M. Aircraft power systems: technology, state of the art, and future trends. IEEE Aerospace and Electronic Systems Magazine, 2000, 15, (1), pp 28-32.

5. https://www.plm.automation.siemens.com/it_it/products/lms/imagine-lab/amesim/

6. http://www.3ds.com/products-services/catia/products/dymola.

7. https://uk.mathworks.com/products/simulink/index.html.

8. Schettini, F., Denti, E., Di Rito, G. and Galatolo, R. Simulation of an all-electric flight control system for the evaluation of power consumption, Proceedings of 29th Congress of the International Council of the Aeronautical Sciences (ICAS), 7-12 September, 2014, St. Petersburg, Russia.

9. Di Rito, G. and Galatolo, R. Experimental assessment of the dynamic stiffness of a fault-tolerant fly-by-wire hydraulic actuator, Proceedings of the Institution of Mechanical Engineers, Part G, $J$ Aerospace Engineering, June 2012, 226, (6), pp 679-690.

10. Di Rito, G., Denti, E. and Galatolo, R. Object-oriented modelling of flight control actuation system for power absorption assessment. Proceedings of the $27^{\text {th }}$ Congress of the International Council of the Aeronautical Sciences (ICAS), 19-24 September, 2010, Nice, France.

11. Denti, E., Di Rito, G., Galatolo, R. and Schettini, F. Power absorption characterisation of electro-mechanical flight control actuators via detailed system modelling, Proceedings of CEAS Air\&Space Conference $-21^{\text {st }}$ AIDAA Congress, 24-28 October, 2011, Venice, Italy, pp 19671973.

12. Di Rito, G., Galatolo, R. and Schettini, F. Experimental and simulation study of the dynamics of an electro-mechanical landing gear actuator. Proceedings of the $30^{\text {th }}$ International Council of the Aeronautical Sciences (ICAS), 25-30 September, 2016, Daejeon, South Korea.

13. Di Rito, G., Denti, E. and Galatolo, R. Development and experimental validation of real-time executable models of primary fly-by-wire actuators. Proceedings of the Institution of Mechanical Engineers. Part I: J Systems and Control Engineering, 2008, 222, (6), pp 523-542. 